\title{
Clinicodemographic Profile and Outcome of Patients with Symptomatic Meckel's Diverticulum: Preliminary Findings
}

\author{
Pravin Joshi, ${ }^{1}$ Narayan Belbase, ${ }^{1}$ Rohit Mishra, ${ }^{1}$ Mukesh Karki ${ }^{1}$ \\ ${ }^{1}$ Department of Surgery, College of Medical Sciences-Teaching Hospital, Bharatpur, Chitwan, Nepal.
}

\begin{abstract}
Background: Meckel's diverticulum is the commonest gastrointestinal congenital anomaly. Though most of the cases do not present clinically, they are challenging to diagnose if become symptomatic. Spectrum of clinical presentation may be different from umbilical fistula, omphalomesenteric cyst to fibrous band from diverticulum to umbilicus. Bleeding, obstruction and infection are the most common complications. Vast majority of them are detected only intra-operatively.
\end{abstract}

Methods: We analyzed our patients who were intra-operatively diagnosed as symptomatic Meckel's Diverticulum. Socio-demographic profile and immediate outcome of operated patients was analyzed from patient's records.

Results: Total nine patients were operated for symptomatic Diverticulitis. All patients were diagnosed intraoperatively. Intestinal obstruction was the most common presentation. Diverticulectomy was the most common procedure performed followed by wedge resection and segmental bowel resection.

Conclusions: Symptomatic Meckel's Diverticulum is difficult to diagnose pre-operatively. Vast majority of them are found only intra-operatively. Most of the patients do well after resection of Meckel's Diverticulum.

Keywords: Meckel's diverticulum; surgery; symptoms.

\section{INTRODUCTION}

Meckel's diverticulum was first described by Fabricius Hildanus in 1598. The name derives from the German anatomist Johann Friedrich Meckel, who described the embryological and pathological features in 1809. ${ }^{1}$ Meckel's diverticulum is the most common congenital anomaly of the gastrointestinal tract. It results from incomplete obliteration of the vitelline duct leading to the formation of a true diverticulum of the small intestine. ${ }^{2}$ Meckel's diverticula are uncommon and often clinically silent, particularly in the adult. Asymptomatic Meckel's diverticulum may be discovered during abdominal exploration for the evaluation of unrelated pathology. Less commonly, they are found incidentally on diagnostic imaging. The persistence of the omphalomesenteric duct beyond fetal development may result in a variety of anatomic patterns, including omphalomesenteric cysts, omphalomesenteric fistulae that drain through the umbilicus and fibrous bands from the diverticulum to the umbilicus that can predispose to bowel obstruction. ${ }^{3,4}$ The most common form is a diverticulum without additional attachment, commonly referred to as Meckel's diverticulum. ${ }^{5}$ The rich blood supply to the diverticulum is provided by the vitelline artery, which is a branch of the superior mesenteric artery.

Most of the cases of Meckel's diverticulum are without complication; however complications develop in $4 \%$ of cases as gastrointestinal bleeding, obstruction and perforation leading to secondary peritonitis. ${ }^{6}$ Meckel's diverticulum occurs in approximately $2 \%$ of the population with equal incidence in males and females. ${ }^{7}$ It is located on the antimesenteric border of the ileum 45 to $60 \mathrm{~cm}$ proximal to the ileocecal valve and is usually $3-5$ cm long. ${ }^{8}$ It has its own blood supply from the superior mesenteric artery, which makes it vulnerable to infection and obstruction like appendix. ${ }^{9}$ Since cell lining of vitelline duct are pluripotent, we may get heterotopic gastric mucosa (50\%), pancreatic mucosa (5\%) and less commonly colonic mucosa, endometriosis, hepatobiliary tissue,

Correspondence: Dr. Pravin Joshi, Department of Surgery, College of Medical Sciences-Teaching Hospital, Bharatpur, Chitwan, Nepal. Email:drpravin2008@gmail.com. Phone: +977-9857024449. Article received: 2019-12-18. Article accepted: 2020-03-03. 
which are responsible for other complications like hemorrhage, ${ }_{10,11}$ chronic peptic ulceration and perforation. ${ }^{0,11}$

\section{METHODS}

This is a cross-sectional study conducted in College of Medical Sciences, Bharatpur from a period of 2012 to 2018. We analyzed our patients who presented to us with symptoms of acute abdomen and who were intra-operatively diagnosed to have complication of Meckel's Diverticulum. Analysis of patients presenting complain, treatment provided in hospital and immediate post-operative outcomes was done. We had published case reports of our intial cases on Meckel' Diverticulum in Journal of medical College of Medical Sciences 2013, Vol. 1, No. 03 and cases in that study were also included in the current analysis.

\section{RESULTS}

There were total nine patients who were diagnosed as a case of Meckel's diverticulum intraoperatively, none of the patients were suspected of having complication of Meckel's Diverticulum before surgery. Six patients presented clinically as Acute Small Bowel Obstruction and three patients presented with the clinical picture of Acute Appendicitis. The age ranged from 15 to 33 years old with mean age of 21 . All patients were male and abdominal pain was the most consistent symptom, in 8 patients. Pain was located centrally at periumbilical region initially which later became diffuse over whole abdomen, associated with vomiting and distention in 6 patients and localized to Right Iliac fossa in 3 patients. Two patients had pain only in right iliac fossa (RIF) and 1 patient had pain generalized but more in the right iliac fossa. The clinical diagnosis of acute small bowel obstruction was made based upon the clinical findings of distended abdomen and dilated small bowel loop and air fluid level in supine and erect abdominal X-Ray. Presence of RIF pain and tenderness and presence of rebound tenderness with laboratory finding of leukocytosis were considered as sufficient clinical and laboratory findings to make a diagnosis of Acute appendicitis. Also, the preoperative diagnosis of acute appendicitis was supported by the collection noted at Right iliac fossa in ultrasonographic study among all three patients, however appendix was not visualized. WBC count was raised above 12000 in all patient with RIF pain and 2 patients with features of acute small bowel obstruction. There were no significant past medical and surgical history in any patient.

All patients under went surgical exploration with the provisional diagnosis of acute small bowel obstruction or acute appendicitis and the intra-operative finding were noted. The position of
Meckel's Diverticulum varied from 15 to $90 \mathrm{~cm}$ from Ileocaecal junction. Six diverticulum were found to have wide neck and the length varied from $5 \mathrm{~cm}$ to $10 \mathrm{~cm}$, while three had narrow neck and length was more than $8 \mathrm{~cm}$ in all three. In cases presenting as obstruction: 4 had diverticulitis with ileal loop adhered to Diverticulum and leading dilation of proximal bowel loop, 1 patient had a band from Meckel's diverticulum to anterior abdominal wall and in 1 patient the Diverticulum itself had rotated around the ileum and leading to obstruction. In all cases the diverticulum was found to be erythematous and edematous with fibrinous plaque over it and adjacent small bowel loop. Among patients with pain localized to RIF; diverticula were localized between 15 to $30 \mathrm{~cm}$ from ileocecal junction and gangrenous change was seen in one patient. Six patients underwent diverticulectomy, 2 patients with broad base and smaller length were planned for wedge resection. In one of the patients presenting as acute appendicitis, the Meckel's diverticulum was found at $16 \mathrm{~cm}$ proximal to Ileocaecal junction and the diverticulum was found to be intensely erythematous with beefy red color that had involved $8 \mathrm{~cm}$ of adjacent distal and proximal ileum as well. The patient was subjected to resection of the involved proximal and distal segments with end to end anastomosis of the ileum. Postoperatively, the recovery was unremarkable. Intra-operatively appendix was found normal in all cases but prophylactic appendectomy was done for all 9 patients. No adverse event occurred in postoperative period. Surgical site infection (SSI) was noted in two patients with incision line erythema and some purulent discharge from the surgical wound; both were managed as superficial SSI with removal of stitches, drainage of pus and antibiotics. All patients had received prophylactic pre-operative antibiotic, Ceftriaxone. Drain was kept in patient who underwent ileal resection.

\section{DISCUSSION}

Lower gastrointestinal hemorrhage is the most common clinical presentation of Meckel diverticulum in children, with incidence rates recorded as high as $50 \% .{ }^{11}$ The average age of presentation is 2 years but it may occur in older children and adults. ${ }^{12,13}$ The presence of heterotopic gastric and pancreatic mucosa within the Meckel's diverticulum, which secretes acid and highly alkaline pancreatic secretion respectively, causing ulceration of adjacent ileal mucosa, is the main pathophysiology behind this. However, in adults, other rare causes of bleeding from Meckel's diverticulum have been noted which include the stromal tumors of the diverticulum. ${ }^{14}$ Children often present with dark red or maroon stool or stool mixed with blood and mucus, whereas adults usually present with melena and crampy abdominal 
pain. Intestinal obstruction is more common in adults and less commonly seen in children. The reason for intestinal obstruction is either volvulus of a loop of bowel around the diverticulum or band and intussusceptions of the diverticulum into small bowel. $^{15}$

Diverticulitis is also frequently seen in older children and adults. Clinically it is very difficult to differentiate Meckel's diverticulitis from appendicitis. A delay in diagnosis of the inflammatory condition may lead to perforation. A perforated Meckel's divertivulum presents like small intestine perforation. A symptomatic Meckel's diverticulum is indication for surgery. Diverticulectomy or segmental resection can be done, however for a bleeding Meckel's diverticulum segmental resection is recommended. ${ }^{16,17}$ Laparoscopic Meckel's diverticulum surgery is safe and with the benefit of possibility of examining rest of the abdominal cavity in cases of diagnostic uncertainties. ${ }^{18} 99 \mathrm{mTc}$ pertechnate is at present the investigation of choice in suspected bleeding from Meckel diverticulum; its diagnostic sensitivity, specificity and accuracy has been reported as high as $85 \%, 95 \%$, and $90 \%$, respectively in the pediatric age group. Angiography may also be useful for localization of the site of bleeding and diagnosis. ${ }^{19}$ To date, few data are available regarding the role of capsule endoscopy and double-balloon enteroscopy for diagnosis of Meckel's Diverticulum. Krstic et al. in a retrospective study of 157 Capsule Endoscopies for gastrointestinal bleeding showed that the diagnostic yield of Capsule Endoscopy for Meckel's Diverticulum was $18.6 \%{ }^{20}$ He et al. in a retrospective study of 74 patients with surgically proven Meckel's diverticulum submitted preoperatively to Capsule Endoscopy or Double Baloon Enteroscopy for gastrointestinal bleeding showed that the diagnostic yield of Capsule Endoscopy and retrograde Double Baloon Enteroscopy for Meckel's Diverticulum was 7.7\% and $86.5 \%$, respectively. In our cases bleeding was not the presenting complain of the patients which is probably because of the age factor. Bleeding is more common in younger children $<2$ years of age but our patients were all above 10 years of age. None of the cases were diagnosed preoperatively and since all the cases were presented as acute surgical abdomen demanding emergency surgery it was decided not to spend precious hours searching for a definite cause of acute abdomen before surgery.

\section{CONCLUSIONS}

Meckel's Diverticulum is a well known clinical entity that might present in early or late childhood or even in adults. Pre-operative diagnosis is difficult as it usually presents like acute abdomen and mimicking conditions like acute appendicitis or acute small bowel obstruction. However, outcome is excellent in vast majority of patients if timely surgical intervention is implemented.

\section{REFERENCES}

1. Pollak Raymond. Adjunctive Procedure in Intestinal Surgery. In: Fischer JE, editor. Mastery of surgery. Fifth. 2007. pp. 1392 $-1393$

2. Sagar J, Kumar V, Shah DK. Meckel's diverticulum: a systematic review. J R Soc Med 2006; 99:501.

3. Passarge E, Stevenson RE. Meckel's diverticulum. In: Human malformations and related anomalies, 2nd, Stevenson RE, Hall JE (Eds), Oxford University Press, Oxford 2006. p.1111.

4. Simms MH, Corkery JJ. Meckel's diverticulum: its association with congenital malformation and the significance of atypical morphology. $\mathrm{Br}$ J Surg 1980; 67:216.

5. Yahchouchy EK, Marano AF, Etienne JC, Fingerhut AL. Meckel's diverticulum. J Am Coll Surg 2001; 192:658.

6. Turgeon DK, Barnett JL: Meckel's diverticulum. Am J Gastroenterol 1990, 85:777781.

7. Evers BM. Small Intestine. In: Townsend CM, editor. Sabiston Textbook of Surgery. 17. Elsevier; 2004. pp. 1366-1368.

8. Mortensen NJ, Jones O. The Small and Large

Intestines. In: Russell RCG, Williams NS, Bulstrode CJK Arnold, editor. Bailey \& Love's Short Practice of Surgery. 24. 2004. pp. 11591160.

9. Whang EE, Ashley SW, Zinner MJ. Small intestine. In: Brunicardi FC, editor. Schwartz's Principles Of Surgery. eighth. McGraw-Hill; 2005. pp. 1043-1044.

10. Yamaguchi M, Takeuchi S, Awazu S. Meckel's diverticulum: investigation of 600 patients in Japanese literature. Am J Surg. 1978;136:247249. doi: 10.1016/0002-9610(78)90238-6.

11. Stewart IC. Neurovascular hamartoma in a Meckel's diverticulum. $\mathrm{Br} \mathrm{J}$ Clin Pract. 1985;39:411-2.

12. Mortensen NJ, Jones O. The Small and Large Intestines. In: Russell RCG, Williams NS, Bulstrode CJK Arnold, editor. Bailey \& Love's Short Practice of Surgery. 24. 2004. pp. 1159 1160.

13. Rutherford RB, Akers DR. Meckel Diverticulum: A review of 148 pediatric patients with specific reference to the pattern of bleeding and to mesodiverticular vascular bands. Surgery. 1966;59:618-26.

14. Bărbulescu M, Burcoş T, Ungureanu CD, Zodieru-Popa I. Stromal tumor of Meckel's 
diverticulum - a rare source of gastrointestinal bleeding and a real diagnostic problem. Chirurgia (Bucur) 2005;100:69-73.

15. Epu S. Axial volvulus of a giant meckel's diverticulum. Abdominal Surgery. 2007.

16. Park JJ, Wolff BG, Tollefson MK, Walsh EE, Larson DR. Meckel diverticulum: the Mayo Clinic experience with 1476 patients (19502002). Ann Surg. (2005) 24:529-33. 10.1097/01.sla.0000154270.14308.5f

17. Mukai M, Takamatsu H, Noguchi H, Fukushige T, Tahara H, Kaji T. Does the external appearance of a Meckel's diverticulum assist in choice of the laparoscopic procedure?. Pediatr Surg Int. (2002)18:231-3. 10.1007/ s003830100663.
18. Palanivelu C, Rangarajan M, Senthilkumar R, Madankumar MV, Kavalakat AJ. Laparoscopic management of symptomatic Meckel's diverticula: a simple tangential stapler excision. JSLS. 2008;12:66-70.

19. Kotecha M, Bellah R, Pena AH, Jaimes C, Mattei P. Multimodality imaging manifestations of the Meckel diverticulum in children. Pediatr Radiol. (2012) 42:95-103. 10.1007/s00247-011 $-2252-7$

20. Krstic SN, Martinov JB, Sokic-Milutinovic AD, Milosavljevic TN, Krstic MN. Capsule endoscopy is useful diagnostic tool for diagnosing Meckel's diverticulum. Eur J Gastroenterol Hepatol. (2016) 28:702-7. 10.1097/MEG.0000000000000603.

Citation: Joshi P, Belbase N, Mishra R, Karki M. Clinicodemographic Profile and Outcome of Patients with Symptomatic Meckel's Diverticulum: Preliminary Findings. JCMS Nepal. 2020; 16(1):37-40. 